\title{
Development and Psychometric Study of the Academic Life Satisfaction Scale (ALSS) in a Higher Education Students Sample
}

\section{Nogueira $\mathrm{MJ}^{1 *}$, Antunes JP2 and Sequeira $\mathrm{C}^{3}$}

${ }^{1}$ School of Health, Catholic University of Portugal, Portugal

${ }^{2}$ School of Health, Polytechnic Institute of Setubal, Portugal

${ }^{3}$ School of Nursing, Center for Health Technology and Services Research, Portugal

*Corresponding author: Maria José Carvalho Nogueira, School of Health, Catholic

University of Portugal, Fábrica da Pólvora de Barcarena, 2730-036, Barcarena, Portugal, Tel: 00351214398200 ; Email: nogueira.mjc@gmail.com

\section{Abstract}

This study aimed to develop and test the psychometric properties of the self-administered academic life satisfaction scale (ALSS) in a Portuguese sample of undergraduate students. An instrument development design process and psychometric study was performed. The data were collected between October and December 2016 in Lisbon campuses. The content and face validity analysis were performed by using a focus group. The ALSS's psychometric study was performed on a 500-undergraduate student's convenience sample. The participants were invited to fill out an online questionnaire: sociodemographic data; one self-perception question about academic performance; and the ALSS. The Principal Component Analysis (PCA) and Cronbach's $\alpha$ internal consistency was performed. The reliability, verified through internal consistency, showed to be adequate (Cronbach's $\alpha=0.80$ ). A two-dimensions structure construct validity was established by PCA, explaining $42.90 \%$ of total variance. The criterion validity was demonstrated by positive significative correlations between ALSS academic self-perception performance. The ALSS is a valid, reliable and very brief selfresponse instrument that is now available to measure academic life satisfaction among Portuguese students. It can be used to support more accurate health promotion programs in the campuses to improve student's academic success, wellbeing and mental health.

Keywords: Higher Education; Sociodemographic; Nursing

Abbreviations: ALSS: Academic Life Satisfaction Scale; ALS: Academic Life Satisfaction; SSQ: Student Satisfaction Questionnaire; CSS: College Student Survey; SSI: Student Satisfaction Inventory; ASQ: Academic Satisfaction Questionnaire; ASSCS: Academic Satisfaction Scale for College Students; PCA: Principal Components Analysis.

\section{Introduction}

\section{Background}

The Academic Life Satisfaction Scale (ALSS) measure the student's academic experiences on campus and the quality of their adjustment to the academic life and 


\section{Nursing \& Healthcare International Journal}

environment. The development procedure of the ALSS is based on the literature review and Multidimensional Model of Adjustment of Young People to the University context [1].

Currently, academic life satisfaction (ALS) plays an important role im campus, both as a key indicator of students' well-being, as well as an institutional measure of success and effectiveness [2]. ALS refers to the student's perception of positive feelings and attitude towards his/her learning activities [3]. Globally encompasses student life experiences in the academic environment and shows the quality of campus [4,5]. Happy students with their studies (considered "satisfied") adopts an active learning attitude, while unhappy's (considered "dissatisfied") adopts a negative or passive attitude [6]. The degree of student satisfaction is the margin between "level of anticipation" and "actual results" so, a smaller margin would mean greater satisfaction and a larger margin would mean lower satisfaction [7].

In addition, ALS is a complex multifactorial construct that includes a broad of students' life experiences on campus and shows the quality of students' adaptation to academic environment. These aspects have leading to a debate centred on ALS's construct and measurement [3]. Therefore, over the past two decades the discussion about students' ALS reliable instruments remains [8]. literature review point out three aspects to be considered to measure students' ALS: (1) higher education transition is a vulnerability period with multiple and complex adjustment tasks and setting specificities; (2) adaptation tasks involve students' personal characteristics and may disturb their health and performance (3) students' ALS play a significant role in measuring institutional effectiveness $[1,3,9]$.

Overall, authors agree that transition and adjustment to academic life is a major challenge for freshman, that involves academic satisfaction, developmental aspects (personal, social and vocational), as well the academic environment and features of attended campus [10]. The positive accomplishment of this transition includes academic satisfaction, which in turn depends on the degree of each surpassed challenge by the students. Currently, the main developmental students tasks involved in this period are grouped in four domains: (a) academic - to continuous adaptations to new learning strategies, teaching and evaluation system; (b) personal to establish identity, expand self-awareness, develop selfesteem and a personal view of the world; (c) social - to develop progressively more mature interpersonal relationships (family, colleagues, teachers, colleagues of the opposite sex and authority figures); (d) vocational - to strength vocational identity and decision making, to explore and commit with professional goals [3,11].

Because student's ALS involves a complex multifactorial process of experiences (personal, affective, cognitive aspects and institutional features and facilities), it is difficult to limit and identify the ALS's construct components [3]. Hence, there is no consensus about to how to measure the students' ALS accurately $[9,12]$. However, understanding the underlying dimensions of student's ALS as well the factors that contribute to student's satisfaction has a great potential benefit for institutions, students and society [8].

\section{Literature Review}

Literature shows a lack of instruments to gather data about students' self-perceptions of academic satisfaction and experiences on campus [4]. Nevertheless we find some relevant instruments such as: the Student Satisfaction Questionnaire [13], with 70 items and 5 subscales (comprehension, social life, work conditions, recognition and educational quality); the College Student Survey [14], with 27 items and 5 subscales (curriculum and teaching, services and support, student life, relationships with teachers and conditions and equipment); and the Student Satisfaction Inventory [15], original version (79 items) and the short one (6 items). Yet, these instruments assign insufficient attention to interpersonal (relations), academic (course) and setting (institution) dimensions, covering merely intrapsychic variables, such as cognitive and psychosocial aspects $[12,7]$

In the late nineties, in Portugal, some instruments were developed to screen and study Portuguese students' adjustment processes to obtain success in the first years of college. Mostly based on MMAU model [12,3], point that student's academic adjustment does not occur dissociated from human's development or learning processes, on the contrary, it covers dimensions such as: satisfaction with the pedagogical relationships with teacher; physical environment and facilities of the campus; personal commitment to the course; extracurricular activities on campus; setting facilities to study; students skills and competences; self-perception of academic performance; and relationship with colleagues and teachers $[1,3,4]$.

In the scope of MMAU's the concept of ALS is grounded on student's personal issues and academic setting. From this point of view, ALS is the students' subjective assessment of the quality and value of the 


\section{Nursing \& Healthcare International Journal}

academic experience, combining cognitive and affective components. This model covers students' personal characteristics, interpersonal relationship with teachers and colleagues, the quality of the curriculum and teaching, as well the conditions provided by the campus environment $[3,12]$.

A second perspective, defines ALS as students' perception about the educational experience that includes the personal commitment and involvement with the college, and the decision to stay or leave the college. It covers cognitive-affective dimensions (socio-relational, personal, interpersonal, institutional and curricular aspects), and circumstantial settings of the campus (grounds, buildings and arrangements) [2]. This conception accepts that ALS is a dynamic concept, so it is variable along students' academic path, as well influenced by them personal characteristics $[1,7]$.

In Portuguese-speaking countries, regardless the lack of tools to measure ALS, literature review show four important self-report instruments: (1) Questionnaire of Academic Experience [2], with 60 items and 5 dimensions' structure: personnel (13 items $\alpha=0,87)$; interpersonal (13 items $\alpha=0,86)$; career (13 items $\alpha=0,91$ ); learning (13 items $\alpha=0,82$ ); institutional ( 8 items $\alpha=0,71$ ), that explain $41,7 \%$ of the variance. The Brazilians short version [16], has 55 items and the same 5 dimensions and total Cronbach's alpha is 0,88; (2) The Academic Satisfaction Questionnaire [2], with 13 items and 3 dimensions: curricular satisfaction (5 items $\alpha=0,74$ ); satisfaction with the institution ( 4 items $\alpha=0,64)$; socio-relational satisfaction (4 items $\alpha=0,66$ ), that explain $51 \%$ of the variance and total Cronbach's alpha $=0,78$; (3) the Satisfaction with Academic Experience Scale [17], with 35 items and 3 dimensions: satisfaction with course $(13$ items $\alpha=0,90$ ); opportunities and development (10 items $\alpha=0,87$ ); satisfaction with the institution (11 items $\alpha=$ 0,87 ) that explain $47,7 \%$ of the variance and total Cronbach's alpha $=0,94$ and subsequent studies also show good psychometric properties [3]; (4) and the Academic Satisfaction Scale for College Students [12], with 35 items and 4 dimensions: pedagogic milieu (11 items $\alpha=0,87$ ); affectivity (10 items $\alpha=0,76$ ); campus milieu (7 items $\alpha=$ 0,73 ); self-esteem (7 items $\alpha=0,72$ ) that explain $41,8 \%$ of the variance.

However, despite the evidence of good psychometric properties, in terms of validity and precision, most of the instruments above differ in terms of variables and dimensions, showing some lack of constructs strength $[3,5,7]$. Also, they are to extensive, meticulous or very specific and do not address important aspects of ALS construct - such as personal and setting elements, which are central dimensions to adjustment process to college [4]. We decided to develop a new potential instrument to measure ALS based on a theoretical framework that contents the student's unique perception of life satisfaction and the peculiarities of campus, both dimensions equally involved on students' academic life experience. Hence, the purpose of this study is to develop and to test psychometric properties on the selfadministered ALSS in a Portuguese student's sample.

\section{Methods}

\section{Participants}

The pilot version of the ALSS was tested in a sample of 500 freshmen and sophomore students attending Military, public and private universities and institutes from Lisbon district, Portugal. We appraised the sample size sufficient to obtain sensible psychometric estimations and we set up the inclusion criteria: aged between 18 and 24 years old; and to be Portuguese native speaker. The inquiry form to collect information was anonymous and voluntary. The return fill rate was $68 \%$.

\section{Materials}

To collect data we use: an sociodemographic form with six items (sex, marital status, hometown, area of study, year of attendance); a single self-classification question to measure student's self-perception of academic performance (rating in a 5-point Likert-type scale; range from $1=$ very low to $5=$ excellent); and the ALSS pilot version - a eight-items self-report instrument designed by the authors to measure student's ALS, which comprises academic experiences and good adjustment to the academic life on campus. The ALSS yields a global score and two dimensions: (1) Personal Satisfaction (internal - students' skills and competences, perception of academic performance and relationships with colleagues and teachers; items 5, 6, 7, 8) and (2) Satisfaction with the Academic Environment (external - physical, pedagogical environment, interest and commitments to the course, extracurricular activities of the institution, conditions for study; items 1, 2, 3, 4). It rates in a 5-point Likert-type scale, all positive (range from: $1=$ Strongly disagree; 2 =Strongly disagree; 3 =Neither agree nor disagree; 4 =Agree; $5=$ = totally agree). ALSS's total score is the sum of all items, that can vary from a minimum of eight to a maximum of forty. The higher value of ALSS, the best student's self-perception of academic life satisfaction in campus. 


\section{Nursing \& Healthcare International Journal}

\section{Procedure}

Based on literature review, frist a list of items was carefully selected regarding to: personal, career, interpersonal, study, satisfaction with the course, opportunity for development and satisfaction with the institution, from two instruments, underlying theoretical MMAU model variables. Second, we used ten students focus group interview methodology to select the most relevant items (score rank) that express events and issues that occur during life in campus. This group items were reviewed by an expert panel to verify the clarity, pertinence and suitability of the selected items. Finally, a pilot version facial validity was appraised by a different group of fifteen students using the Thinking Aloud Method [18], to analyse the adequacy, acceptability of the items and to check if the wording used was clear. After minor lexicon adjustments, a corrected eight items pilot version was produced named ALSS.

After formal authorizations, all students were invited to participate. The data was collected during October to December 2016 thru an online query using an access link sent to students' campus email. After logged in on platform, students had to validate the Informed Term of Consent to access and fill the socio demographic, academic information and other measures.

Statistical analysis was performed with SPSS 20.0. Psychometric evaluation of the ALSS was conducted in successive phases. To determine item-to-total correlations, item-to-dimension correlations and total Cronbach's alpha we use Personal Satisfaction and Satisfaction with the Academic Environment dimensions. To determine the underlying factor structure in the ALSS was used the Principal Components Analysis (PCA).
Convergent validity was examined using Spearman correlation coefficient (rho). We assumed that adequate reliability would be coefficients above 80 , for both analyses.

The present investigation complies with all ethical principles assumed by Helsinki Declaration and Human Subjects Protection; in addition it was approved by the Ethics Committee Review Board of the institutions involved. All participants were previously asked to validate written informed consent before voluntarily fill the online survey form, provided with information on the purpose and implications of the study. Also, they were informed that all data would remain anonymous, and without any possibility of identifying the participants. All were informed of their right to withdraw from the study at any time.

\section{Results}

A 500 non-probabilistic sample of higher education students, with average age of 19.60 years (range 18-24), mostly female (99.30\%) and single (79.60\%). The majority $(78.80 \%)$ attend public institutions and military (3,90\%); 2nd year (51.10\%) and mostly (61.30\%) health courses. A large number perceives academic performance as good $(60.90 \%)$ and $1.30 \%$ as excellent. The results display on Table 1 show a moderate satisfaction with academic life (M=29.20; $\mathrm{SD}=5.33)$. The Personal Satisfaction $(\mathrm{M}=14.61 ; \mathrm{SD}=2.90)$ obtained a slightly higher value than Satisfaction with Academic Environment $(\mathrm{M}=14.59 ; \mathrm{SD}=3.20)$. The Item 2 got the highest value of mean satisfaction $(M=4.24)$ and item 3 the lowest $(\mathrm{M}=2.97)$.

\begin{tabular}{|l|c|c|}
\hline \multicolumn{1}{|c|}{ ALSS } & M & DP \\
\hline 8. I am satisfied with the relationship that I have with the teachers & 3.68 & 0.9 \\
\hline 6. I am satisfied with my academic performance & 3.39 & 0.96 \\
\hline 5. I am satisfied with my commitment to my course & 3.63 & 1.01 \\
\hline 7. I am satisfied with the relationship that I have with my colleagues on campus & 3.91 & 1.02 \\
\hline Personal Satisfaction $\left({ }^{a}\right) \alpha=.72$ & $\mathbf{1 4 . 6 1}$ & $\mathbf{2 . 9 2}$ \\
\hline 4. I am satisfied with the conditions for studying at campus & 3.47 & 1.17 \\
\hline 1. I am satisfied with the institution of higher education that I attend & 3.92 & 1.02 \\
\hline 3. I am satisfied with the extracurricular activities of the institution I attended & 2.97 & 1.21 \\
\hline 2. I am satisfied with the course I attended & 4.24 & 0.92 \\
\hline Satisfaction with Academic Environment ${ }^{(b)} \alpha=.74$ & $\mathbf{1 4 . 5 9}$ & $\mathbf{3 . 1 9}$ \\
\hline Total Scale ${ }^{(c)} \alpha=.80$ & $\mathbf{2 9 . 2}$ & $\mathbf{5 . 3 3}$ \\
\hline
\end{tabular}

(a) 4 Items [4;20]; (b) 4 items [4;20]; (c) ALSS [8;40]

Table 1: Means, SD and internal consistency of ALSS' items and components.

Nogueira MJ, et al. Development and Psychometric Study of the Academic Life Satisfaction Scale (ALSS) in a Higher Education Students Sample. Nurs Health Care Int J 2019, 3(2): 000183. 


\section{Nursing \& Healthcare International Journal}

The independence of the items was studied using Pearson's inter-item correlation Table 2. All correlations were positive, significant $(\alpha=0.01)$ and ranged between the lower $r=0.12$ and higher value $r=0.62$. The corrected item-total correlation varied between 0.40 and 0.56 . Only item 6 had a lower value, yet acceptable.

\begin{tabular}{|c|c|c|c|c|c|c|c|}
\hline \multirow{2}{*}{ Items } & \multicolumn{7}{|c|}{ ALSS } \\
\hline & 2 & 3 & 4 & 5:00 AM & 6:00 AM & $7: 00 \mathrm{AM}$ & 8:00 AM \\
\hline $1^{b}$ & 0.52 & 0.38 & 0.5 & 0.38 & 0.3 & 0.3 & 0.34 \\
\hline $2^{b}$ & & 0.29 & 0.3 & 0.55 & 0.39 & 0.17 & 0.31 \\
\hline $3^{b}$ & & & 0.4 & 0.36 & 0.26 & 0.2 & 0.27 \\
\hline $4^{b}$ & & & & 0.34 & 0.17 & 0.12 & 0.24 \\
\hline 5 & & & & & 0.62 & 0.35 & 0.45 \\
\hline 6 & & & & & & 0.26 & 0.42 \\
\hline 7 & & & & & & & 0.45 \\
\hline
\end{tabular}

Table 2: Pearson Correlations ALSS inter-item.

To investigate ALSS's psychometric qualities we search for evidence of validity related to the internal structure and dimensions. The Principal Components Analysis (PCA) extraction factor method was performed with Varimax Orthogonal Rotation, which assumes the independence between the bent factors. The results of Bartlett's sphericity test [Chi-square (28) =1198.968; P= $0.00<0.001]$ indicates that the correlations between the items are suitable to carry out the analysis. The Kaiser Meyer - Olkin measurement $(\mathrm{KMO}=0.77>0.5)$ confirmed the fitness of the sample for the factorial analysis, and all Anti-Matrix values were higher than 0.71 (assuming 0.30 as minimum acceptable of practical significance by Marôco [19]. The results of initial PCA analysis showed that two components obeyed the Kaiser criterion, and the scree plot Figure 1 showed two components placed before the curve inflection. So, considering the sample size and the convergence between the scree plot and the Kaiser criterion, it was decided that 2 was the number of components to kept in the final analysis.

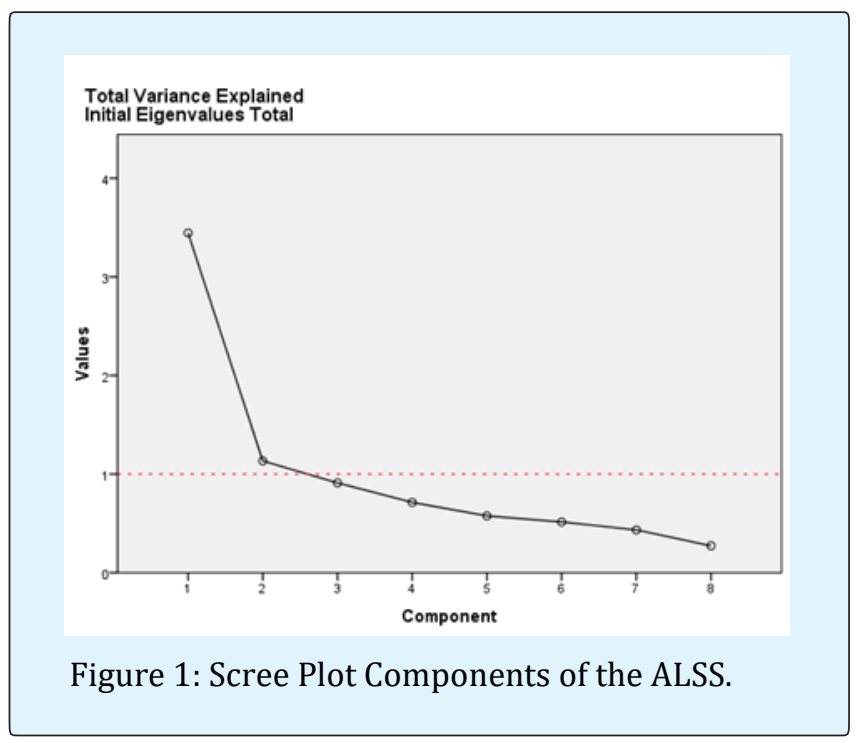

Table 3 shows the structure and components of the ALSS (Varimax Factor Analysis - Orthogonal Rotation). Rotated matrix showed that items 5, 6, 7 and 8 had a higher load on component 1 - Personal Satisfaction, and a whose relationship with factor 2 , ranged from 0.68 to 0.74 . The items 1, 2, 3 and 4, had a higher load in Component 2
- Satisfaction with Academic Environment, and the ratio ranged between 0.54 and 0.83 . The eigenvalue of Component 1 explains $29.50 \%$ of the variance and Component 2 explains 27.70\%. The Component 1 best explains the total variance of $43.10 \%$, while the the 


\section{Nursing \& Healthcare International Journal}

second explains $14.20 \%$. Both Components explain an accumulated variance of $57.24 \%$.

\begin{tabular}{|l|c|c|}
\hline \multicolumn{1}{|c|}{ Items } & \multicolumn{1}{c|}{ Components } \\
\cline { 2 - 3 } & $\mathbf{1}$ & $\mathbf{2}$ \\
\hline SP 8 - I am satisfied with the relationship that I have with the teachers & $\mathbf{0 . 7 4}$ & \\
\hline SP 6 - I am satisfied with my academic performance & $\mathbf{0 . 7 3}$ & $\mathbf{0 . 7 1}$ \\
\hline SP 5 - I am satisfied with my commitment to my course & $\mathbf{0 . 6 8}$ & \\
\hline SP 7 - I am satisfied with the relationship that I have with my colleagues at campus & 0.8 \\
\hline SAE 4 - I am satisfied with the conditions for studying at campus & 0.7 \\
\hline SAE 1 - I am satisfied with the institution of higher education that I attend & 0.7 \\
\hline SAE 3 - I am satisfied with the extracurricular activities of the institution I attended & 0.5 \\
\hline SAE 2 - I am satisfied with the course I attended & $\mathbf{2 . 3 6}$ & $\mathbf{2}$ \\
\hline Eigenvalues & $\mathbf{2 9 . 5}$ & $\mathbf{2 8}$ \\
\hline \% explained variance & $\mathbf{4 3 . 1}$ & $\mathbf{5 7}$ \\
\hline \% cumulative explained variance Kaiser normalization. & & \\
\hline PS - Personal Satisfaction; SAE-Satisfaction with Academic Environment; varimax orthogonal rotation method with \\
\hline
\end{tabular}

Table 3: Structure (a) and components of ALSS.

The two subscales of ALSS, empirically created, contain items that represent the intrinsic characteristics of each factor theoretically supported the Personal Satisfaction consists of items that represent predominantly personal features while Satisfaction with Academic Environment comprises contextual aspects of satisfaction with academic life.

The reliability of ALSS was assessed through internal consistency, using Cronbach's alpha coefficient. Accuracy of the ALSS items is display on Table 3. Results indicate good reliability for total scale $\alpha=0.8$, and acceptable for both subscales (above the reference value 0.7) and considering the reduced number of ALSS items [19].

Convergent validity was calculated using Spearman's correlation between ALSS and a self-perception single question "are you satisfied with your academic performance?" to measure personal academic performance. The results show a significant $(p<0.01)$ positive correlation between self-perception of academic performance and ALSS ( $r=36)$, varying from the higher intensity in Personal Satisfaction ( $r=41)$ to the lowest in Satisfaction with Academic Environment $(r=, 24)$.

\section{Discussion}

The purpose of this study was to develop and test psychometric properties on the self-administered ALSS in a Portuguese student's sample. We like to highlight the importance of the student's ALS to better understand, improve and change campus environments, thereby creating settings more healthy and favourable for Portuguese Higher Education student's development. Measuring ALS is an important indicator of the institution's responsiveness to the students' needs $[4,8,20]$, well-being and psychological distress [21]. In this sense, we looked for evidence related to a new instrument-AISS, towards reliability, internal structure and face validity.

The results of internal consistency indicate good reliability for ALSS's total scale and acceptable for the two subscales. These accuracy results are significant considering the small number of items of the ALSS. Cronbach's alpha consistency stood above the reference value (0.7) suggested by Marôco [19]. Also, content validity of ALSS was established. The Principal Components Analysis-performed on ALSS's items showed that the scale is a valid and reliable measure. The results display the existence of two dimensions: one linked to intrinsic and uniqueness nature of students and, a second one more external, related to institutional influences like circumstantial issues. This two-dimension structure indicates compliance between the underlying construct of ALSS and the conceptual framework of the MMAU Model $[7,3]$. This structure configuration is in line with several studies that have confirmed the multidimensionality of ALS $[1,3,13]$. Overall, these results also comply with the construct of previous similar instruments, that includes several areas related to student's life and experiences in campus, which usually polarize around two areas: inner and external dimension namely: personal and sociorelational satisfaction and college characteristics environment [3]. Both, individual and environmental, 


\section{Nursing \& Healthcare International Journal}

variables have shown to be strongly related to academic adjustment as well, made significant contributions to predict student's psychological welfare [9]. Also, ALS is a relevant indicator to explain student's health, self-efficacy and stress [22-24]. Similarly, some authors have linked higher levels of student's well-being with higher levels of ALS, and there is evidence that student's ALS influences academic success and integration [3,8,25-27] and as a predictor of higher education drop-out [5]. The significant positive correlations between ALSS and a self-perception single question enabled to assess convergent validity with alike measure, confirming similarity between the underlying constructs of the both measures. Likewise, the relevance of ALSS is because it is very short. Hence it is an important alternative to the current similar instruments, since they are very extensive and exhaustive.

Since this study is a ALSS's pilot analysis, authors find these results promising, because they add an important alternative tool to measure ALS, and so to fill the lack of reliable and specific instruments. However, Researchers consider that further studies must be carry out to reproduce and test psychometric properties of ALSS in different samples to confirm and increase the robustness of the ALSS, namely stability over time, convergent validity and validity in different Portuguese and Portuguesespeaking samples.

In conclusion, the results of the analyses carried out on ALSS's psychometric characteristics have shown to be adequate reliable and valid. ALSS is a short self-response instrument and is now available to measure academic life satisfaction among Higher Education Portuguese students. Because ALSS is easily and very brief instrument, it can be used as an important alternative tool in research, since the existing instruments are very extensive or exhaustive. Also, it can be used as a screening tool to support more accurate health promotion programs in campuses to improve student's academic success, wellbeing and mental health. Despite the usefulness and adequacy of this new instrument to evaluate ALS, further studies should be carried out to strengthen the psychometric properties of ALSS.

Given the ALSS shows good psychometric properties, it is as a suitable, useful and easily tool to measure academic life satisfaction, both for clinical and research purposes. The results of the study are relevant to nursing practice, as they add a new reliable and valid instrument to evaluate the student's ALS. Reliable instruments are important tools to provide healthcare professionals with the necessary assessment mean to increase and improve accurate interventions. Given the scarcity of instruments to measure ALS, this novel, short, valid and reliable instrument is an asset to practice that may aid how to better help students in a variety of settings.

\section{Conflict of Interests}

Authors declare no conflict of interests related to research process or writing of this paper. The present research as no funding sources.

\section{References}

1. Soares A, Almeida L, Dinis A, Guisande A (2006) Multidimensional Model of Youth Adjustment to the University context (MMAU): Study with students of science and technology versus social and human sciences. Psychological Analysis 24(1): 15-27.

2. Almeida LS, Soares AP, Ferreira JA (2002) Academic Experience Questionnaire (QVA-r): Evaluation of the adjustment of university students. Psychological Assessment 2: 81-93.

3. Santos A, Polydoro S, Scortegagna S, Linden M (2013) Integration to Higher Education and Academic Satisfaction in University Students. Psychology: science and profession 33(4): 80-793.

4. Nogueira MJ (2018) Measuring Academic Life Satisfaction in Portuguese Students. Nursing \& Healthcare International Journal 2(1): 000136.

5. Fadel CB, de Souza JA, Bordin D, Garbin CA, Garbin AJ, et al. (2018) Satisfaction with the academic experience among graduate students of a brazilian public university. RGO-Revista Gaúcha de Odontologia 66(1): 50-59.

6. Bardagi M, Hutz C (2012) Academic Routine and Relationship with Colleagues and Teachers. Impact on University Evasion 43(2): 174-184.

7. Soares A, Mourão L, Mello T (2011) Study for the construction of an instrument of academic-social behaviour for university students. Studies and Research in Psychology. Rio de Janeiro 11(2): 488506.

8. Reysen R, Degges White S, Reysen M (2017) Exploring the Interrelationships among Academic Entitlement, Academic Performance, and Satisfaction with Life in a College Student Sample. Journal of College Student Retention: Research, Theory \& Practice. 


\section{Nursing \& Healthcare International Journal}

9. Ramos A, Barlem J, Lunardi V, Barlem E, Silveira R (2015) Satisfaction with academic experience among undergraduate nursing students. Texto \& ContextoEnfermagem 24(1): 187-195.

10. Santos A, Suehiro A (2007) Instruments for Assessment of Integration and Academic Satisfaction: Validity Study. Revista Galego-Portuguesa de Psicoloxía e Educación14(1).

11. Almeida L, Guisande M, Paisana J (2012) Extracurricular involvement, academic adjustment and achievement in higher education: A study of Portuguese students. Annals of Psycology 28(3): 860865.

12. Sisto F, Muniz M, Bartholomeu D, Pasetto P, Oliveira A, et al. (2008) Study for the construction of Academic Satisfaction Scale for University Students. Psychological Evaluation 7(1): 45-55.

13. Betz EL, Klingensmith JE, Menne JW (1970) The measurement and analysis of college student satisfaction. Measurement and Evaluation in Counseling and Development 3(2): 110-118.

14. HERI (2017) Overview of Surveys, Higher Education Research Institute.

15. Noel-Levitz Study of Strategic Recruitment collection (2003) Archives Record Series, University Archives, Rod Library, University of Northern Iowa.

16. Granado JI, Santos AA, Almeida L, Soares A, Guisande MA (2005) Academic integration of university students: Contributions for the adaptation and validation of QVA-r in Brazil. Psychology and Education 4(2): 31-41.

17. Schleich A, Polydoro S, dos Santos A (2006) Scale of satisfaction with the academic experience of students of higher education. Aval Psicol 5(1): 11-20.

18. Someren M, Barnard Y, Sandberg J (1994) The Think Aloud Method. A practical guide to modelling cognitive processes, Academic Press, London, pp: 208.
19. Marôco J (2011) Statistical Analysis with SPSS Statistics $5^{\text {th }}$ (Edn.), Pero Pinheiro.

20. Zhou M, Lin W (2016) Adaptability and Life Satisfaction: The Moderating Role of Social Support. Front Psychol 7: 1134.

21. Nogueira MJ, Sequeira C (2018) Satisfaction with academic life. Relation with well-being and psychological distress. Portuguese Society of Mental Health Nursing 6: 71-76.

22. Santos L, Veiga F, Pereira A (2010) Welfare, emotional symptoms and interpersonal difficulties of students of higher education. In Proceedings of the VII National Symposium on Research in Psychology, Braga: University of Minho, pp: 2652-2662.

23. Chow $H$ (2010) Predicting academic success and psychological wellness in a sample of Canadian undergraduate students. Electronic Journal of Research in Educational Psychology 8(2): 473-496.

24. Mahmoud J, Staten R, Hall L, Lennie T (2012) The Relationship among Young Adult College Students' Depression, Anxiety, Stress, Demographics, Life Satisfaction, and Coping Styles. Issues in Mental Health Nursing, 33(3): 149-156.

25. Rosinha A, Coelho M (2010) Academic Performance and Adaptation to Military Higher Education. Economy \& Business, Luisíada 10: 141-160.

26. Almeida LS, Soares AP, Ferreira JA (2000) Transition and adaptation to the University: Presentation of the Academic Experience Questionnaire (QVA). Psychology 19(2): 189-208.

27. Almeida L, Ferreira J, Soares AP (2001) Academic Experience Questionnaire: Construction and validation of a reduced version (QVA-r). Portuguese Pedagogy Review 3: 181-207. 